\title{
PENERAPAN METODE PREWITT, CANNY DAN SOBEL PADA PROSES DETEKSI TEPI CITRA
}

\author{
Polinus Laia \\ Program Studi Teknik Informatika, STMIK Budi Darma, Medan, Indonesia \\ Jalan Sisingamangaraja No. 338, Medan, Indonesia
}

\begin{abstract}
Abstrak
Deteksi tepi merupakan langkah pertama untuk melengkapi informasi di dalam citra dimana tepi mencirikan batas - batas objek yang berguna untuk proses identifikasi. Banyak metode dalam deteksi tepi, namun dalam penelitian ini metode yang diambil yaitu metode prewitt, metode canny dan metode sobel untuk mendeteksi tepi objek pada citra digital. Sistem ini diterapkan ketiga metode tersebut untuk meningkatkan penampakan garis batas suatu objek. Penelitian ini membahas tentang cara penerapan ketiga metode tersebut dalam aplikasi matlab 7.1. Tujuan dan manfaat aplikasi ini adalah untuk mengenal penerapan hasil dari deteksi tepi serta memperoleh informasi awal mengenai fitur deteksi tepi untuk pengenalan objek bagi peneliti selanjutnya.
\end{abstract}

Kata Kunci: Deteksi Tepi, Prewitt, Canny, Sobel

\section{Abstract}

Edge detection is the first step to completing information in an image where the edges characterize object boundaries that are useful for the identification process. There are many methods of edge detection, but in this study, the methods taken are the Prewitt method, the CANNY method and the Sobel method to detect the edges of objects in digital images. This system applies all three methods to improve the appearance of the boundary line of an object. This study discusses how to apply the three methods in the application Matlab 7.1. The purpose and benefits of this application are to recognize the application of the results of edge detection and obtain initial information about the edge detection features for object recognition for future researchers.

Keywords: Edge Detection, Prewitt, Canny, Sobel

\section{PENDAHULUAN}

Permasalahan yang sering muncul dalam citra adalah vignetting. Vignetting adalah gejala munculnya area gelap pada tepi citra, terutama di pojok-pojoknya. Kondisi ini terjadi saat diameter citra yang dihasilkan lensa lebih kecil dari sensor yang disebabkan oleh tiga hal yaitu dengan penggunaan lensa yang tidak tepat pada kamera dengan sensor yang lebih besar, halangan fisik pada sisi muka lensa (yang biasanya berupa penggunaan filter yang terlalu tebal) dan kualitas desain lensa yang kurang optimal. Salah satu solusi penyelesaian masalah tersebut adalah melalui deteksi tepi.

Deteksi tepi sangat penting dalam pengolahan citra karena pendeteksian tepi merupakan langkah pertama untuk melingkupi informasi di dalam citra. Tepi mencirikan batas-batas objek, karena itu tepi berguna untuk proses segmentasi dan identifikasi objek dalam citra. Tujuan pendeteksian tepi adalah untuk meningkatkan penampakan garis batas suatu daerah atau objek di dalam citra (Puji Triono, Murinto, 2015, 1116).

Metode prewitt menggunakan persamaan yang sama dengan operator sobel, hanya saja konstanta $c$ yang digunakan bernilai 1. Operator prewitt tidak menekankan pembobotan pada piksel - piksel yang lebih dekat dengan titik pusat kernel (T. Sutoyo, Edy Mulyanto, Vincent Suhartono, Oky Dwi Nurhayati, Wijanarto, 2009). Pengembangan dari gradient operator dengan menggunakan 2 mask (horizontal dan vertikal) ukuran $3 \times 3$. Operator ini kekuatan gradient ditinjau dari sudut pandang horizontal dan vertikal memperhatikan titik disekitar pada posisi horizontal dan vertikal.

Metode canny yang dikemukakan oleh John Canny pada tahun 1986, terkenal sebagai operator deteksi tepi yang optimal. Algoritma ini memberikan tingkat kesalahan rendah, melokalisasi titik-titik tepi (jarak piksel-piksel yang ditemukan deteksi dan tepi yang sesungguhnya sangat pendek) dan hanya memberikan satu tanggapan untuk satu tepi (Abdul Kadir, Adhi Susanto, 2013). Metode sobel merupakan salah satu operator yang menghindari adanya perhitungan gradient di titik interpolasi. Operator ini menggunakan kernel ukuran 3x3 piksel untuk perhitungan gradient sehingga perkiraan gradient berada tepat di tengah jendela (T. Sutoyo, Edy Mulyanto, Vincent Suhartono, Oky Dwi Nurhayati, Wijanarto, 2009). Biasanya operator sobel menempatkan penekanan atau pembobotan pada piksel-piksel yang lebih dekat dengan titik pusat jendela, sehingga pengaruh piksel-piksel tetangga akan berbeda sesuai dengan letaknya terhadap titik di mana gradient dihitung. Susunan nilai-nilai pembobotan pada jendela terlihat bahwa perhitungan terhadap gradient juga merupakan gabungan dari posisi horizontal dan posisi vertikal.

Mendeteksi tepi citra merupakan langkah untuk menyelesaikan permasalah vignetting pada gambar (citra) dengan menerapkan metode prewitt, canny dan sobel. Penerapan tiga metode ini dilakukan secara individu (satu persatu) dengan tujuan yang sama adalah mendapatkan tepi citra. Penerapan metode prewitt, canny dan sobel dalam sebuah aplikasi deteksi tepi citra berbasis GUI (Grafic User Interface) dari Matlab 7.1 dapat membantu 
mendeteksi tepi citra untuk mengambil informasi permasalahan vignetting dalam sebuah citra sehingga ada pertimbangan kepada pengelolah memperbaiki kualitas gambar (citra).

\section{TEORITIS}

\subsection{Deteksi Tepi}

Deteksi tepi berfungsi untuk memperoleh tepi objek. Deteksi tepi memanfaatkan perubahaan nilai intensitas yang drastis pada batas dua area. Defenisi tepi di sini adalah himpunan piksel yang terhubung yang terletak pada batas dua area. Perlu diketahui, tepi sesungguhnya mengandung informasi sangat penting. Informasi yang diperoleh dapat berupa bentuk maupun ukuran objek (Abdul Kadir, Adhi Susanto, 2013).

\subsection{Metode Prewitt}

Metode prewitt menggunakan persamaan yang sama dengan operator sobel, hanya saja konstanta $c$ yang digunakan bernilai 1. Operator prewitt tidak menekankan pembobotan pada piksel - piksel yang lebih dekat dengan titik pusat kernel. Metode ini mengambil prinsip dari fungsi laplacian yang dikenal sebagai fungsi untuk membangkitkan High Pass Filter (T. Sutoyo, Edy Mulyanto, Vincent Suhartono, Oky Dwi Nurhayati, Wijanarto, 2009).

$$
S x=\left[\begin{array}{ccc}
1 & 0 & -1 \\
1 & 0 & -1 \\
1 & 0 & -1
\end{array}\right] \text { dan } S y=\left[\begin{array}{ccc}
-1 & -1 & -1 \\
0 & 0 & 0 \\
1 & 1 & 1
\end{array}\right]
$$

\subsection{Metode Canny}

Metode canny yang dikemukakan oleh John Canny pada tahun 1986, terkenal sebagai operator deteksi tepi yang optimal. Algoritma ini memberikan tingkat kesalahan rendah, melokalisasi titik-titik tepi (jarak piksel-piksel yang ditemukan deteksi dan tepi yang sesungguhnya sangat pendek) dan hanya memberikan satu tanggapan untuk satu tepi (Abdul Kadir, Adhi Susanto, 2013).

\subsection{Metode Sobel}

Metode sobel merupakan salah satu operator yang menghindari adanya perhitungan gradient di titik interpolasi. Operator ini menggunakan kernel ukuran 3x3 piksel untuk perhitungan gradient sehingga perkiraan gradient berada tepat di tengah jendela. Misalkan susunan piksel- piksel di sekitar piksel x, y (T. Sutoyo, Edy Mulyanto, Vincent Suhartono, Oky Dwi Nurhayati, Wijanarto, 2009) adalah:

\begin{tabular}{|c|c|c|}
\hline$a_{0}$ & $a_{1}$ & $a_{2}$ \\
\hline$a_{7}$ & $(\mathrm{x}, \mathrm{y})$ & $a_{3}$ \\
\hline$a_{6}$ & $a_{5}$ & $a_{4}$ \\
\hline
\end{tabular}

Berdasarkan susunan piksel tetangga tersebut besaran gradient yang dapat dihitung menggunakan operator sobel (T. Sutoyo, Edy Mulyanto, Vincent Suhartono, Oky Dwi Nurhayati, Wijanarto, 2009).

\section{ANALISA DAN PEMBAHASAN}

Tahapanyang digunakan untuk mendeteksi tepi citra menggunakan ketiga operator prewitt, canny dan sobel yaitu tahap ekstraksi warna, tahap croping, tahap deteksi tepi menggunakan metode prewitt, canny dan sobel, tahap operasi dilatasi citra, tahap pengisian objek, pembuatan garis tepi untuk meyelsaikan permasalahan vignetting. Prosedur dalam mendeteksi tepi citra sebagai berikut:

1. Image Acquisition

Akuisisi citra merupakan tahap awal, pada tahap ini citra akan diambil/ditangkap. Kamera akan dipergunakan untuk tahapan ini. Kamera yang umum dipergunakan pada tahap ini, dapat berupa kamera digital.

2. Pra Processing

Pada Tahap ini dilakukan proses grayscale terhadap citra yang akan dideteksi tepi citranya.

1) Proses grayscalling : proses untuk mengubah gambar yang memiliki warna menjadi gambar yang memiliki tingkat warna ke abu-abuan (grayscale).

2) Gambar yang akan di-gray-scalling nilai tiap titik akan disamakan dengan nilai red-green-bluenya sehingga untuk tiap titik hanya memiliki 1 nilai saja, yang disebut nilai gray-level-nya.

3) Pada dasarnya proses ini dilakukan dengan meratakan nilai pixel dari 3 nilai RGB menjadi 1 nilai.

3. Segmentasi (Segmentation)

Pada tahap ini citra yang telah diubah menjadi grayscale akan dideteksi tepi citranya menggunakan operator prewitt, canny dan sobel.

4. Post Processing 
Pada tahap ini akan dihasilkan citra yang berupa citra yang hanya terdiri dari gambar hitam putih yang memiliki garis tepi citra.

Berikut merupakan tabel grayscale citra.

Tabel 1. Hasil Proses Perubahan Citra RGB ke Grayscale

\begin{tabular}{|l|l|l|l|l|l|l|l|}
\hline 51 & 37 & 40 & 41 & 45 & 46 & 46 & 45 \\
\hline 39 & 41 & 42 & 43 & 43 & 40 & 38 & 32 \\
\hline 39 & 43 & 42 & 41 & 37 & 31 & 32 & 17 \\
\hline 44 & 46 & 41 & 34 & 33 & 37 & 45 & 30 \\
\hline 45 & 57 & 37 & 32 & 35 & 42 & 55 & 52 \\
\hline 53 & 48 & 39 & 41 & 47 & 45 & 51 & 56 \\
\hline 52 & 47 & 47 & 50 & 55 & 58 & 55 & 57 \\
\hline 50 & 49 & 51 & 52 & 52 & 54 & 55 & 55 \\
\hline
\end{tabular}

\subsection{Penerapan Operator Prewitt}

Berikut adalah hasil perhitungan perkalian matrix penggunaan operator prewitt untuk mengetahui tepi sebuah gambar citra dengan matrix 8 x 8 . Konvolusi pertama dilakukan terhadap piksel (titik pusat mask).

Tabel 2. Nilai Citra Grayscale Matrix 8 × 8

\begin{tabular}{|l|l|l|l|l|l|l|l|}
\hline 51 & 37 & 40 & 41 & 45 & 46 & 46 & 45 \\
\hline 39 & 41 & 42 & 43 & 43 & 40 & 38 & 32 \\
\hline 39 & 43 & 42 & 41 & 37 & 31 & 32 & 17 \\
\hline 44 & 46 & 41 & 34 & 33 & 37 & 45 & 30 \\
\hline 45 & 57 & 37 & 32 & 35 & 42 & 55 & 52 \\
\hline 53 & 48 & 39 & 41 & 47 & 45 & 51 & 56 \\
\hline 52 & 47 & 47 & 50 & 55 & 58 & 55 & 57 \\
\hline 50 & 49 & 51 & 52 & 52 & 54 & 55 & 55 \\
\hline
\end{tabular}

1. Konvolusi pertama dilakukan terhadap piksel yang bernilai 41 (titik pusat mask):

$\mathrm{Sx}=(40)(1)+(1)(42)(1)+(42)(1)-(51)(-1)+(1)(39)(-1)+(39)(-1)=253$

Sy $=(51)(1)+(1)(37)(1)+(40)(1)-(39)(-1)+(1)(43)(-1)+(42)(-1)=252$

Maka: $M=\sqrt{S_{x}^{2}+S_{y}^{2}}=505=\mathbf{2 2}$

2. Konvolusi kedua dilakukan terhadap piksel yang bernilai 42 (titik pusat mask):

$\mathrm{Sx}=(41)(1)+(1)(43)(1)+(41)(1)-(37)(-1)+(1)(41)(-1)+(43)(-1)=246$

$\mathrm{Sy}=(37)(1)+(1)(40)(1)+(41)(1)-(43)(-1)+(1)(42)(-1)+(41)(-1)=244$

Maka: $M=\sqrt{S_{x}^{2}+S_{y}^{2}}=490=\mathbf{2 2}$

3. Konvolusi kedua dilakukan terhadap piksel yang bernilai 42 (titik pusat mask):

$\mathrm{Sx}=(45)(1)+(1)(43)(1)+(37)(1)-(40)(-1)+(1)(42)(-1)+(42)(-1)=249$

Sy $=(40)(1)+(1)(41)(1)+(45)(1)-(42)(-1)+(1)(41)(-1)+(37)(-1)=247$

Maka: $M=\sqrt{S_{x}^{2}+S_{y}^{2}}=496=\mathbf{2 2}$

4. Konvolusi kedua dilakukan terhadap piksel yang bernilai 42 (titik pusat mask):

$\mathrm{Sx}=(46)(1)+(1)(40)(1)+(31)(1)-(41)(-1)+(1)(43)(-1)+(41)(-1)=242$

Sy $=(41)(1)+(1)(45)(1)+(46)(1)-(41)(-1)+(1)(37)(-1)+(31)(-1)=241$

Maka: $M=\sqrt{S_{x}^{2}+S_{y}^{2}}=487=22$

5. Konvolusi selanjutnya sama dengan konvolusi satu, dua, tiga dan empat. Setelah di konvolusikan, maka hasil nilainya terlihat pada tabel berikut:

Tabel 3. Hasil Konvolusi Tepi Citra Matrix 8 x 8

\begin{tabular}{|l|l|l|l|l|l|l|l|}
\hline 51 & 37 & 40 & 41 & 45 & 46 & 46 & 45 \\
\hline 39 & $\mathbf{2 2}$ & $\mathbf{2 2}$ & $\mathbf{2 2}$ & $\mathbf{2 2}$ & $\mathbf{2 2}$ & $\mathbf{2 2}$ & 32 \\
\hline 39 & $\mathbf{2 2}$ & $\mathbf{2 2}$ & $\mathbf{2 2}$ & $\mathbf{2 2}$ & $\mathbf{2 2}$ & $\mathbf{2 2}$ & 17 \\
\hline 44 & $\mathbf{2 2}$ & $\mathbf{2 2}$ & $\mathbf{2 2}$ & $\mathbf{2 2}$ & $\mathbf{2 2}$ & $\mathbf{2 2}$ & 30 \\
\hline 45 & $\mathbf{2 2}$ & $\mathbf{2 2}$ & $\mathbf{2 2}$ & $\mathbf{2 2}$ & $\mathbf{2 2}$ & $\mathbf{2 2}$ & 52 \\
\hline 53 & $\mathbf{2 2}$ & $\mathbf{2 2}$ & $\mathbf{2 2}$ & $\mathbf{2 2}$ & $\mathbf{2 2}$ & $\mathbf{2 2}$ & 56 \\
\hline 52 & $\mathbf{2 2}$ & $\mathbf{2 2}$ & $\mathbf{2 2}$ & $\mathbf{2 2}$ & $\mathbf{2 2}$ & $\mathbf{2 2}$ & 57 \\
\hline 50 & 49 & 51 & 52 & 52 & 54 & 55 & 55 \\
\hline
\end{tabular}


Maka hasil deteksi tepi yang didapat dari perhitungan matrix untuk mengetahui segmentasi pada gambar menggunakan metode prewitt, hasil yang didapat pada perkalian matrix 3x3 dengan citra matrix 8 x 8 pada tabel diatas.

\subsection{Penerapan Operator Canny}

Berikut adalah perhitungan perkalian matrix penggunaan operator canny untuk mengetahui masalah vignetting pada citra dengan matrix 8 × 8 . Konvolusi pertama dilakukan terhadap piksel (titik pusat mask).

Tabel 4. Contoh Nilai Citra Matrix 8 x 8

\begin{tabular}{|l|l|l|l|l|l|l|l|}
\hline 51 & 37 & 40 & 41 & 45 & 46 & 46 & 45 \\
\hline 39 & 41 & 42 & 43 & 43 & 40 & 38 & 32 \\
\hline 39 & 43 & 42 & 41 & 37 & 31 & 32 & 17 \\
\hline 44 & 46 & 41 & 34 & 33 & 37 & 45 & 30 \\
\hline 45 & 57 & 37 & 32 & 35 & 42 & 55 & 52 \\
\hline 53 & 48 & 39 & 41 & 47 & 45 & 51 & 56 \\
\hline 52 & 47 & 47 & 50 & 55 & 58 & 55 & 57 \\
\hline 50 & 49 & 51 & 52 & 52 & 54 & 55 & 55 \\
\hline
\end{tabular}

Menghitung nilai konvolusi pada citra

Persyaratan Konvolusi Citra:

a. Jika hasil konvolusi nilai piksel negatif, maka nilai dijadilkan nol

b. Jika hasil konvolusi nilai piksel > nilai keabuan maksimum 255, maka nilai dijadikan kenilai keabuan maksimum 255.

c. Meng-konvolusi piksel pinggir border diabaikan, sehingga nilai piksel pinggir = nilai pada citra semula.

1. Konvolusi pertama dilakukan terhadap piksel yang bernilai 41 (titik pusat mask):

$$
\begin{aligned}
& \mathrm{Gx}=(40)(-1)+(2)(42)(-1)+(42)(-1)-(51)(1)+(2)(39)(1)+(39)(1)=-332 \\
& \mathrm{~Gy}=(51)(-1)+(2)(37)(-1)+(40)(-1)-(39)(1)+(2)(43)(1)+(42)(1)=-332 \\
& |\mathrm{G}|=\left|\mathrm{G}_{\mathrm{x}}\right|+\left|\mathrm{G}_{\mathrm{y}}\right|=\mathbf{0}
\end{aligned}
$$

2. Konvolusi kedua dilakukan terhadap piksel yang bernilai 42 (titik pusat mask):

$$
\begin{aligned}
& \mathrm{Gx}=(41)(-1)+(2)(43)(-1)+(41)(-1)-(37)(1)+(2)(41)(1)+(43)(1)=-248 \\
& \mathrm{~Gy}=(37)(-1)+(2)(40)(-1)+(41)(-1)-(43)(1)+(2)(42)(1)+(41)(1)=-326 \\
& |\mathrm{G}|=\left|\mathrm{G}_{\mathrm{x}}\right|+\left|\mathrm{G}_{\mathrm{y}}\right|=-80 . \text { Maka nilai menjadi }=\mathbf{0}
\end{aligned}
$$

3. Konvolusi kedua dilakukan terhadap piksel yang bernilai 43 (titik pusat mask):

$$
\begin{aligned}
& \mathrm{Gx}=(45)(-1)+(2)(43)(-1)+(37)(-1)-(40)(1)+(2)(42)(1)+(42)(1)=-334 \\
& \mathrm{~Gy}=(40)(-1)+(2)(41)(-1)+(45)(-1)-(42)(1)+(2)(41)(1)+(37)(1)=-328 \\
& |G|=\left|G_{x}\right|+\left|G_{y}\right|=06
\end{aligned}
$$

4. Konvolusi selanjutnya sama dengan konvolusi satu, dua, dan tiga dan. Setelah di konvolusikan, maka hasil nilainya terlihat pada tabel berikut:

Tabel 5. Hasil Konvolusi Citra Menggunakan Operator Canny

\begin{tabular}{|c|c|c|c|c|c|c|c|}
\hline 51 & 37 & 40 & 41 & 45 & 46 & 46 & 45 \\
\hline 39 & $\mathbf{0}$ & $\mathbf{0}$ & $\mathbf{6}$ & $\mathbf{6}$ & $\mathbf{6}$ & $\mathbf{0}$ & 32 \\
\hline 39 & $\mathbf{0}$ & $\mathbf{0}$ & $\mathbf{6}$ & $\mathbf{6}$ & $\mathbf{6}$ & $\mathbf{0}$ & 17 \\
\hline 44 & $\mathbf{0}$ & $\mathbf{6}$ & $\mathbf{0}$ & $\mathbf{0}$ & $\mathbf{0}$ & $\mathbf{0}$ & 30 \\
\hline 45 & $\mathbf{0}$ & $\mathbf{6}$ & $\mathbf{0}$ & $\mathbf{0}$ & $\mathbf{6}$ & $\mathbf{6}$ & 52 \\
\hline 53 & $\mathbf{6}$ & $\mathbf{0}$ & $\mathbf{6}$ & $\mathbf{0}$ & $\mathbf{6}$ & $\mathbf{6}$ & 56 \\
\hline 52 & $\mathbf{6}$ & $\mathbf{6}$ & $\mathbf{0}$ & $\mathbf{0}$ & $\mathbf{6}$ & $\mathbf{0}$ & 57 \\
\hline 50 & 49 & 51 & 52 & 52 & 54 & 55 & 55 \\
\hline
\end{tabular}

Maka hasil deteksi tepi yang didapat dari perhitungan matrix untuk mengetahui nilai pada gambar 3.4 menggunakan metode canny, hasil yang didapat pada perkalian matrix 3 x 3 dengan citra matrix 8 × 8 .

\subsection{Penerapan Operator Sobel}

Berikut adalah hasil perhitungan perkalian matrix penggunaan operator sobel untuk mengetahui segmentasi sebuah gambar citra dengan matrix 8 x 8 . Konvolusi pertama dilakukan terhadap piksel (titik pusat mask).

Tabel 6. Contoh Nilai Citra Matrix 8 x 8

\begin{tabular}{|l|l|l|l|l|l|l|l|}
51 & 37 & 40 & 41 & 45 & 46 & 46 & 45 \\
\hline
\end{tabular}




\begin{tabular}{|l|l|l|l|l|l|l|l|}
\hline 39 & 41 & 42 & 43 & 43 & 40 & 38 & 32 \\
\hline 39 & 43 & 42 & 41 & 37 & 31 & 32 & 17 \\
\hline 44 & 46 & 41 & 34 & 33 & 37 & 45 & 30 \\
\hline 45 & 57 & 37 & 32 & 35 & 42 & 55 & 52 \\
\hline 53 & 48 & 39 & 41 & 47 & 45 & 51 & 56 \\
\hline 52 & 47 & 47 & 50 & 55 & 58 & 55 & 57 \\
\hline 50 & 49 & 51 & 52 & 52 & 54 & 55 & 55 \\
\hline
\end{tabular}

1. Konvolusi pertama dilakukan terhadap piksel yang bernilai 41 (titik pusat mask):

$\mathrm{Sx}=(40)(1)+(2)(42)(2)+(42)(1)-(51)(-1)+(2)(39)(-2)+(39)(-1)=496$

Sy $=(51)(1)+(2)(37)(2)+(40)(1)-(39)(-1)+(2)(43)(-2)+(42)(-1)=512$

Maka: $M=\sqrt{S_{x}^{2}+S_{y}^{2}}=1008=\mathbf{3 2}$

2. Konvolusi kedua dilakukan terhadap piksel yang bernilai 42 (titik pusat mask):

$\mathrm{Sx}=(41)(1)+(2)(43)(2)+(41)(1)-(37)(-1)+(2)(41)(-2)+(43)(-1)=498$

Sy $=(37)(1)+(2)(40)(2)+(41)(1)-(43)(-1)+(2)(42)(-2)+(41)(-1)=504$

Maka: $M=\sqrt{S_{x}^{2}+S_{y}^{2}}=1002=\mathbf{3 2}$

3. Konvolusi ketiga dilakukan terhadap piksel yang bernilai 43 (titik pusat mask):

$\mathrm{Sx}=(45)(1)+(2)(43)(2)+(37)(1)-(40)(-1)+(2)(42)(-2)+(42)(-1)=504$

Sy $=(40)(1)+(2)(41)(2)+(45)(1)-(42)(-1)+(2)(41)(-2)+(37)(-1)=492$

Maka: $M=\sqrt{S_{x}^{2}+S_{y}^{2}}=996=\mathbf{3 2}$

3 Konvolusi selanjutnya sama dengan konvolusi satu, dua dan tiga. Setelah di konvolusikan, maka hasil nilainya terlihat pada tabel berikut:

Tabel 7. Hasil Konvulasi Tepi Citra Matrix 8 x 8

\begin{tabular}{|l|l|l|l|l|l|l|l|}
\hline 51 & 37 & 40 & 41 & 45 & 46 & 46 & 45 \\
\hline 39 & $\mathbf{3 2}$ & $\mathbf{3 2}$ & $\mathbf{3 2}$ & $\mathbf{3 2}$ & $\mathbf{3 2}$ & $\mathbf{3 2}$ & 32 \\
\hline 39 & $\mathbf{3 2}$ & $\mathbf{3 2}$ & $\mathbf{3 2}$ & $\mathbf{3 2}$ & $\mathbf{3 2}$ & $\mathbf{3 2}$ & 17 \\
\hline 44 & $\mathbf{3 2}$ & $\mathbf{3 2}$ & $\mathbf{3 2}$ & $\mathbf{3 2}$ & $\mathbf{3 2}$ & $\mathbf{3 2}$ & 30 \\
\hline 45 & $\mathbf{3 2}$ & $\mathbf{3 2}$ & $\mathbf{3 2}$ & $\mathbf{3 2}$ & $\mathbf{3 2}$ & $\mathbf{3 2}$ & 52 \\
\hline 53 & $\mathbf{3 2}$ & $\mathbf{3 2}$ & $\mathbf{3 2}$ & $\mathbf{3 2}$ & $\mathbf{3 2}$ & $\mathbf{3 2}$ & 56 \\
\hline 52 & $\mathbf{3 2}$ & $\mathbf{3 2}$ & $\mathbf{3 2}$ & $\mathbf{3 2}$ & $\mathbf{3 2}$ & $\mathbf{3 2}$ & 57 \\
\hline 50 & 49 & 51 & 52 & 52 & 54 & 55 & 55 \\
\hline
\end{tabular}

Maka hasil deteksi tepi yang didapat dari perhitungan matrix untuk mengetahui segmentasi pada gambar menggunakan metode sobel, hasil yang didapat pada perkalian matrix $3 \times 3$ dengan citra matrix 8x8 pada tabel diatas.

Berikut merupakan diagram activity dari perancangan deteksi tepi:

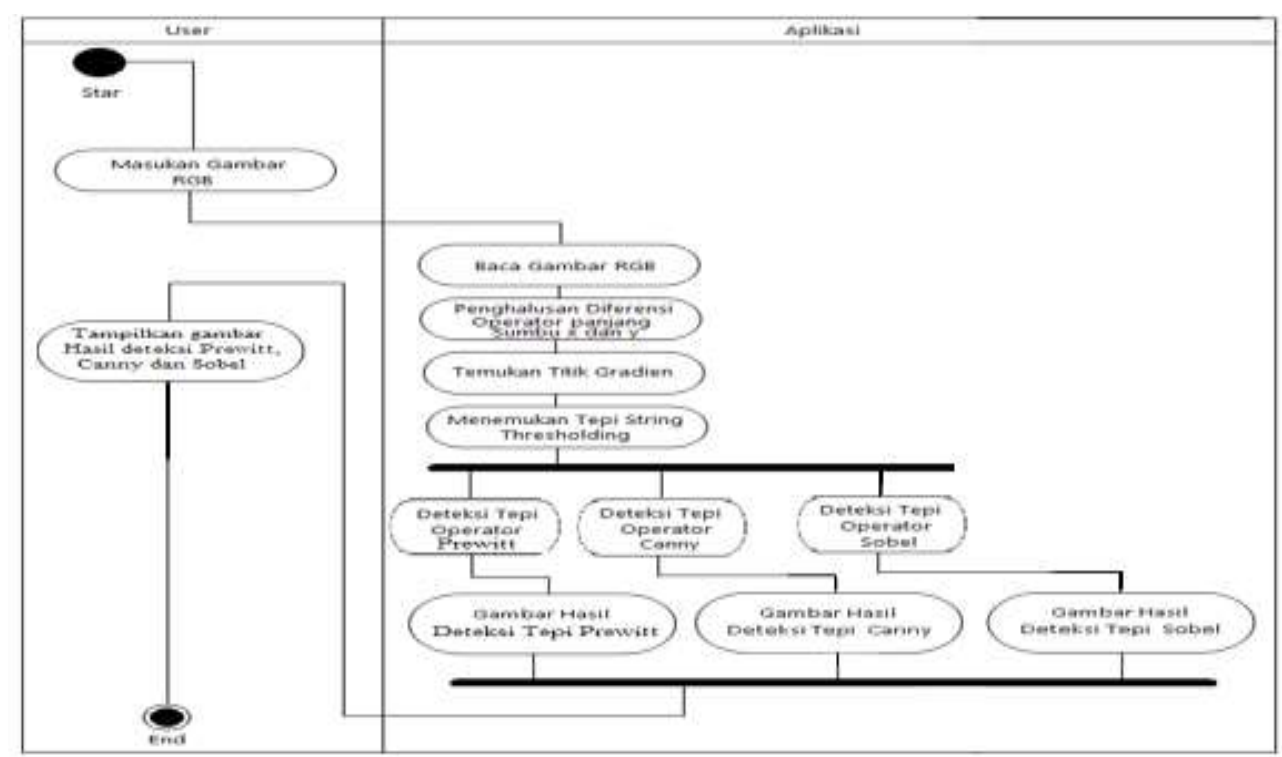

Gambar 1. Activity Diagram Proses Deteksi Tepi Citra

Polinus Laia | http://ejurnal.stmik-budidarma.ac.id/index.php/mib | Page | 49 


\section{KESIMPULAN}

Hasil penelitian dapat ditarik kesimpulan dari deteksi tepi menggunakan 3 metode, adalah:

1. Prosedur dalam mendeteksi tepi itu sangat penting mulai dari pengambil gambar praprocessing, deteksi tepi hingga tahap terakhir mendapatkan tepi yaitu post processing. Perlu diperhatikan bahwa tahap pra processing sangat penting dimana citra harus terlebih dahulu diubah menjadi grayscale.

2. Penerapan metode prewit, canny dan sobel dilakukan satu persatu melalui prosedur - prosedur deteksi tepi. Langkah awal dalam penerapan ini adalah tahap analisa dimana setiap formula akan dilakukan perhitungannya dengan matriks 8x8 sebagai uji coba. Hasil dari perhitungan pada tahap analisa merupakan sebuah tepi citra. Tepi yang dihasilkan dari ketiga metode prewitt, canny dan sobel, lebih optimal tepi yang dihasilkan metode canny dimana garis tepinya lebih tipis dari tepi lainnya.

\section{REFERENCES}

[1] Abdul Kadir, Adhi Susanto “Teori dan Aplikasi Pengelolahan Citra”, Penerbit Andi, Yogyakarta, Edisi I, 2013.

[2] Adi Nugroho, "Rekayasa Perangkat Lunak Berorientasi Objek" Penerbit Andi, Yogyakarta, Edisi I, 2010

[3] Evi Triandini, I Gede Suardika, "Step By Step Desain Proyek Menggunakan UML", Penerbit Andi, Yogyakarta, Edisi I, 2012

[4] Mohammad Yazdi Pusadan, "Pemrograman Matlab Pada Sistem Pakar Fuzzy", Penerbit Deepublish, Yogyakarta, Edisi I, 2014

[5] Muhammad Arhami, S.Si., M.Kom, Anita Desiani, S.Si., M.Kom "Pemrograman Matlab", Penerbit Andi, Yogyakarta, Edisi I, 2005.

[6] Prabowo Pudjo Widodo, Herlawati "Menggunakan UML", Penerbit Informatika, Bandung, 2011.

[7] Susan B. Bastable, "Perawat Sebagai Pendidik" Penerbit EGC, Jakarta, 2012.

[8] T. Sutoyo, Edy Mulyanto, Vincent Suhartono, Oky Dwi Nurhayati, Wijanarto "Teori Pengelolahan Citra Digital," Penerbit Andi, Yogyakarta, Edisi I, 2009 